\title{
Preparation and Characterization of Acacia Catechu Film: Effect of Monomer (HEMA) and UV Radiation
}

\author{
Md. Iftakharul Alam ${ }^{1,2}$, Md. Sahadat Hossain ${ }^{1,2}$, Ruhul A. Khan ${ }^{2, *}$, \\ A. M. Sarwaruddin Chowdhury ${ }^{1}$ \\ ${ }^{1}$ Institute of Radiation and Polymer Technology, Bangladesh Atomic Energy Commission, Dhaka, Bangladesh \\ ${ }^{2}$ Applied Chemistry and Chemical Engineering, University of Dhaka, Dhaka, Bangladesh
}

Email address:

dr.ruhul_khan@yahoo.com (R. A. Khan)

${ }^{*}$ Corresponding author

\section{To cite this article:}

Md. Iftakharul Alam, Md. Sahadat Hossain, Ruhul A. Khan, A. M. Sarwaruddin Chowdhury. Preparation and Characterization of Acacia Catechu Film: Effect of Monomer (HEMA) and UV Radiation. American Journal of Mechanical and Industrial Engineering.

Vol. 4, No. 4, 2019, pp. 64-68. doi: 10.11648/j.ajmie.20190404.12

Received: September 20, 2019; Accepted: October 10, 2019; Published: October 26, 2019

\begin{abstract}
Nature is the prime source of everythings. So, in this research we selected the plant source for the extraction of resin from acacia catechu. Raw acacia catechu was collected from the plant for the extraction of resin and preparation of film. A mixture of $60 \%$ ethanol and $40 \%$ benzene was used as solvent for the extraction of resin. After extraction, polymeric films were prepared by casting the extracted solution maintaining the thickness 1 to $3 \mathrm{~mm}$. Now-a-days monomers are widely used for the improvement of properties. In this case monomer (HEMA) was used to improve the mechanical properties of prepared film. Different percentages $(10,12.5$ and $15 \%)$ of monomer were used with the catechu but $12.5 \%$ showed better results than the others two. Different types of high energy radiation (gamma radiation, UV-radiation, etc.) are also widely used for the improvement of different types of properties. With the HEMA grafted catechu film different pass $(15,20$ and 25$)$ of UV radiation was applied. The highest result was obtained for the $20 \mathrm{UV}$ radiation pass and the monomer concentration was $12.5 \%$ which was taken as optimum. At the optimum condition the highest TS and TM values were $4.5 \mathrm{MPa}$, and $72 \mathrm{MPa}$ respectively as well as the lowest elongation at break was $1.44 \%$.
\end{abstract}

Keywords: Acacia Catechu, UV-radiation, Composites, Monomer, Tensile Property

\section{Introduction}

Catechu is an extract of acacia tree (family: Mimosaceae) and is used for different purposes. It can be extracted from different species but Senegalia catechu (Acacia catechu) is the best source. Ccatechu has antioxidant properties. The main constituents of this plant are catechin and catechu tannic acid along as well as small proportion of brown coloring matter. It also contains tannin, flavotannin, gallotannin, phloratannin, etc [1]. Catechu extract was used in leather tanning, dyeing and preservative for fishing nets [2]. One of the important uses of catechu is medicinal use [3]. The tanning property of catechin in human skin may be supposed to be the active ingredient for the treatment of leucoderma (shiti) [4]. Catechu also has antihormone activity and relations with the vitamin [5]. Catechu is also important ingredient for the preparation of composite materials for different applications. Catechu based composite materials show significant change in their properties [6].

There are different types of methods applied in composites fabrication for the improvement of mechanical properties. The best ways are monomer grafting, high energy radiation, surface modifier, chemical treatment of reinforcing materials, etc. Gamma and UV radiations are the two most widely used high energy radiations. Gamma radiation is a higher energy than the UV radiation. These two radiations are used mostly in composite modification. The source of gamma radiation is 
very costly and the source of UV radiation is less costly. That is why the UV radiation is becoming popular for the radiation application. For the UV radiation application, only the lamp source is required. As the cost of radiation is less, the products prepared by this method are less costly. Another important topic related to this radiation is a health hazard. The hazardous effects of handling the radiation source are relatively less in case of UV radiation than the gamma radiation. These are the main reasons for selecting UV radiation sources for the betterment of mechanical properties of prepared materials [7-11]. Monomer treatment is one of the best methods for the improvement of the properties of the composite materials [12-14]. Different monomer can be use like acrylamide (AA), 2-hydroxyethylmethacrylate (HEMA), methylmethacrylate (MMA), 2-hydroxyethylacrylate (HEA), 1, 6-hexanedioldiacrylate (HDDA), 3-(trimethoxysilyl) propylmethacrylate (TMSPM), and urethane acrylate (UA) [15-18].

In this research, work catechu was extracted with solvent and mechanical characterization was made under different UV radiations.

\section{Materials}

Raw catechu was collected from a local market near Dhaka University, Dhaka, Bangladesh. Monomer HEMA (2Hydroxyethyl-methacrylate) and Methanol were received from E. Merk, Germany. The molecular weight of the HEMA and Methanol was 130.14 and $32.00 \mathrm{~g} / \mathrm{mol}$ respectively. Acetone was collected from the British Drug House Limited and the molecular weight was $58.08 \mathrm{~g} / \mathrm{mol}$.

\section{Methods}

\subsection{Extraction of Pure Catechu}

Raw catechu was collected from plants and preserved at room temperature (25 C). Raw catechu was chopped before mixing in the solvent. Raw catechu was taken in a beaker and in another beaker solvent of ethanol and benzene was prepared with $60 \%$ ethanol and $40 \%$ benzene. Another 1000 $\mathrm{ml}$ beaker was taken for mixing the catechu and solution of $60 \%$ ethanol and $40 \%$ benzene mixture. The solution was mixed for one hour with continuous stirring. After one hour continuous stirring the solution was kept for two hours for settlement. The process was repeated two times for complete mixing of catechu with the solvent. After two times repetition brownish solid resin was found. The brownish solid resin was kept 12 hours for the removal of solvent, ethanol, and benzene As the solvent was toxic the process was done under the fume hood for safety purposes. After the evaporation of benzene and ethanol, solid resin was obtained. The solid was separated and kept for sun drying. Finally dried resin was washed with methanol to remove trace amounts of ethanol and benzene. After removing the solvent, the sample was kept for further characterization.

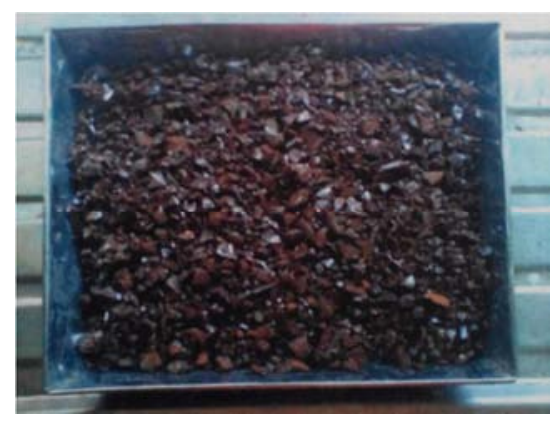

Figure 1. Catechu fragments.

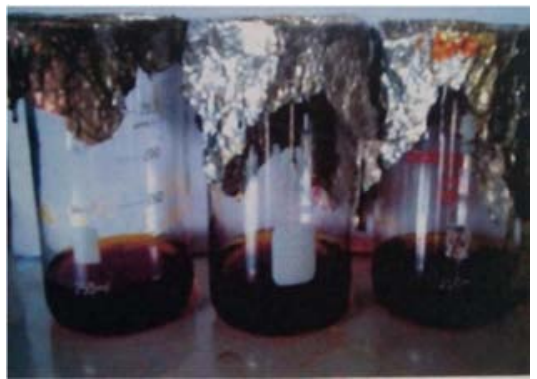

Figure 2. Formulation preparation.

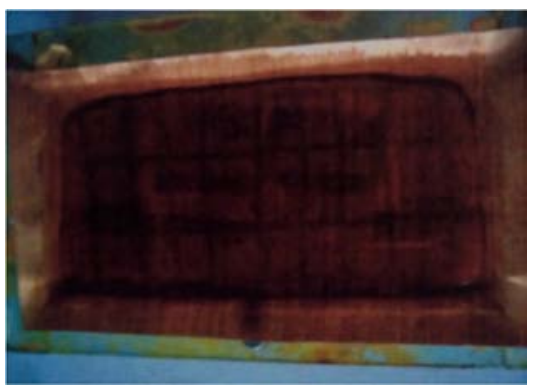

Figure 3. Casting of solution for the preparation of the film.

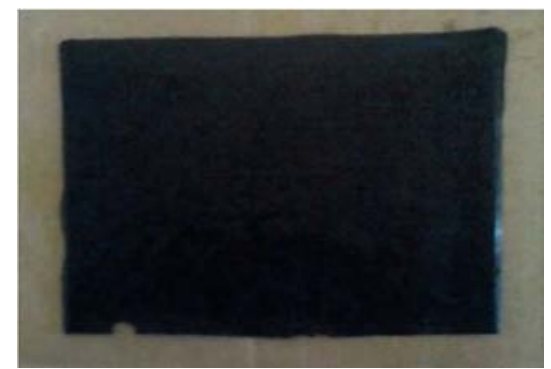

Figure 4. Solid resin for the preparation of the test specimen.

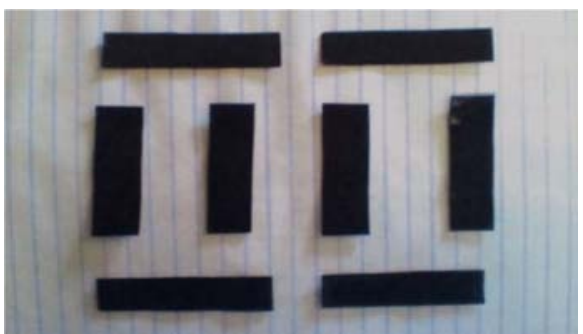

Figure 5. Test specimens.

\subsection{Film Preparation}

In this research, monomer was used to modify the ethe 
film of catechu. Monomer, HEMA (2-Hydroxyethylmethacrylate) was used to prepare the desired film. Most of the data presented in this manuscript are average of at least five samples and the results obtained are within the accuracy of $\pm 1 \%$. In order to modify the physicomechanical properties of the catechu film monomer was used to prepare the film. The solution of monomer was used to prepare the desired film. Different percentages of monomer, HEMA were used for the better properties of prepared film. The monomer was used with the catechu film in different percentages (as 10, 12.5 and $15 \%$ ). Then the films were prepared by casting the solutions in silicon cloth-covered plates.

\section{Results and Discussion}

The prepared catechu films were irradiated under UVradiation with different passes (10, 20 and 25). After irradiation, the TS and TM were increased to some extent but the EB was decreased slightly.

Without radiation $12.5 \%$ HEMA grafted film showed highest TS properties and at 15\% HEMA grafted Lowest TS was obtained. Similar results were observed for the TM properties. On the other hand, lowest EB was observed for $12.5 \%$ HEMA grafted film and highest value was observed for $15 \%$ HEMA grafted film. When different dose of UV radiation was passed through the films there was a little change in mechanical properties. Three dose $(15,20$ and 25 UV-pass) was applied through the film and the best result was obtained from the $20 \mathrm{UV}$-pass. For the $20 \mathrm{UV}$ pass the tensile strength and the tensile modulus was increased $65 \%$ and $30 \%$ respectively relative to the non-irradiated films. On the other hand the elongation at break for the $20 \mathrm{UV}$ pass was $43 \%$ lower than the non-irradiated films. Among the three percentages of the monomer the best results were obtained for the $12.5 \%$ grafted films in all the cases.

The variation of the mechanical properties of the film was maybe for the free radicals production under the different doses of UV pass. As the radiation dose increased the free radical formation was also increased in some extent and consequently the cross-linking was also increased. Thus the tensile strength and the tensile modulus were also increased. But due to the increased cross-linking the elongation at break was decreased. When higher radiation dose was applied there might be the bond breaking of the polymer thus the previously described property changed oppositely. This is the reason of getting highest TS and TM at moderate irradiation say $20 \mathrm{UV}$ pass and the lowest at high $25 \mathrm{UV}$ pass. For the same reason the lowest EB was obtained at moderate UV pass and the highest at high radiation dose. Some free radicals were produced during the UV radiation. The produced free radicals further reacted with themselves and each other. Which made the mechanical properties different from the non-irradiated film of catechu and HEMA.

With the variation of monomer percentages in the catechu film, the mechanical properties were varied. When small percentages of monomer were added, the mechanical properties were increased in some extend. At the $12.5 \%$ monomer grafting, the mechanical properties were highest. But, when more monomer was added with the catechu film the mechanical properties were decreased at certain limit. This is because of the forced transfer of the monomer and catechu. When certain limit of monomer was added to the catechu film the force transfer between the monomer and catechu was increased. But, when more monomer was added, the mechanical properties were decreased. This is because of the barrier of the monomer and catechu.

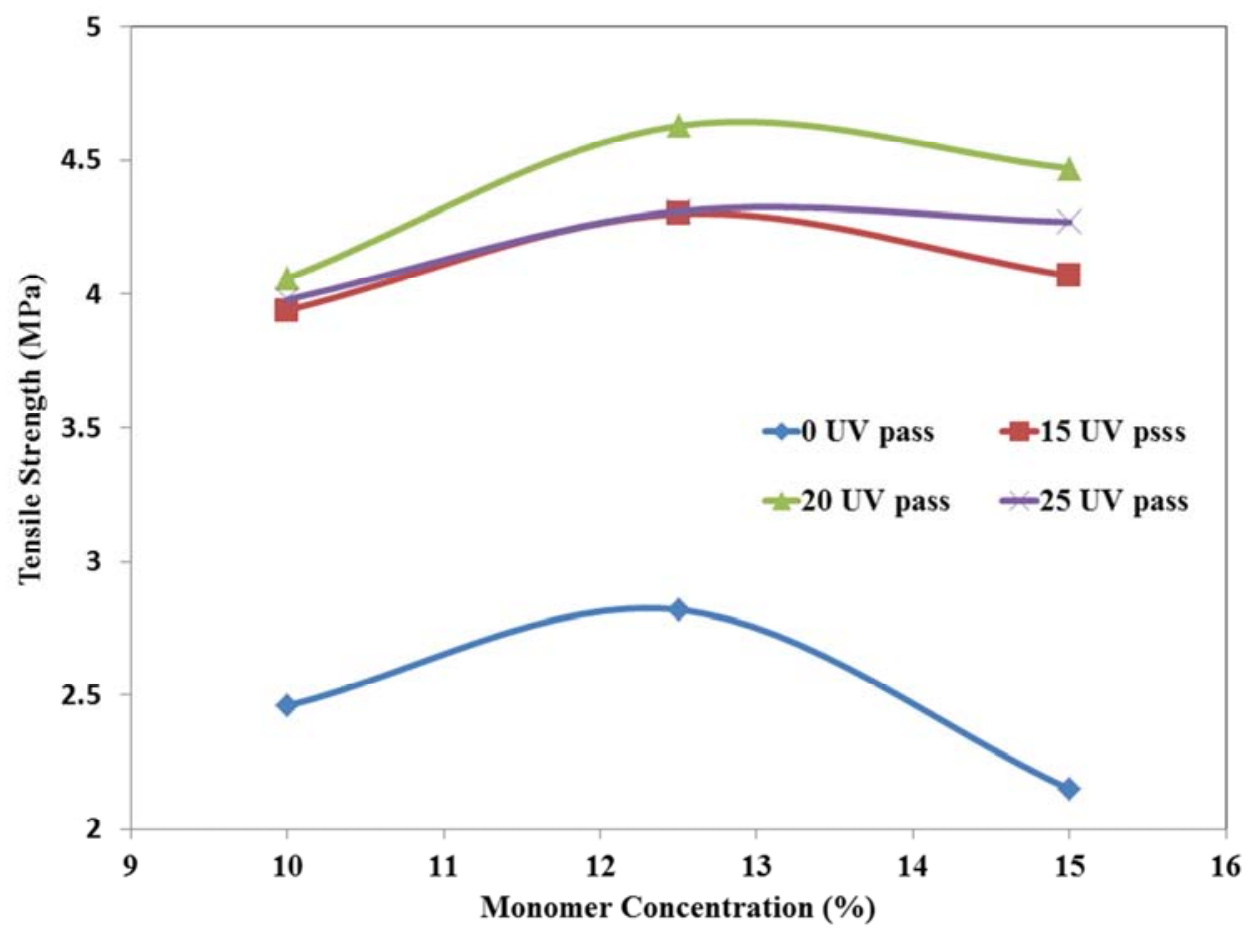

Figure 6. Change of tensile strength at different UV passes and different monomer concentrations. 


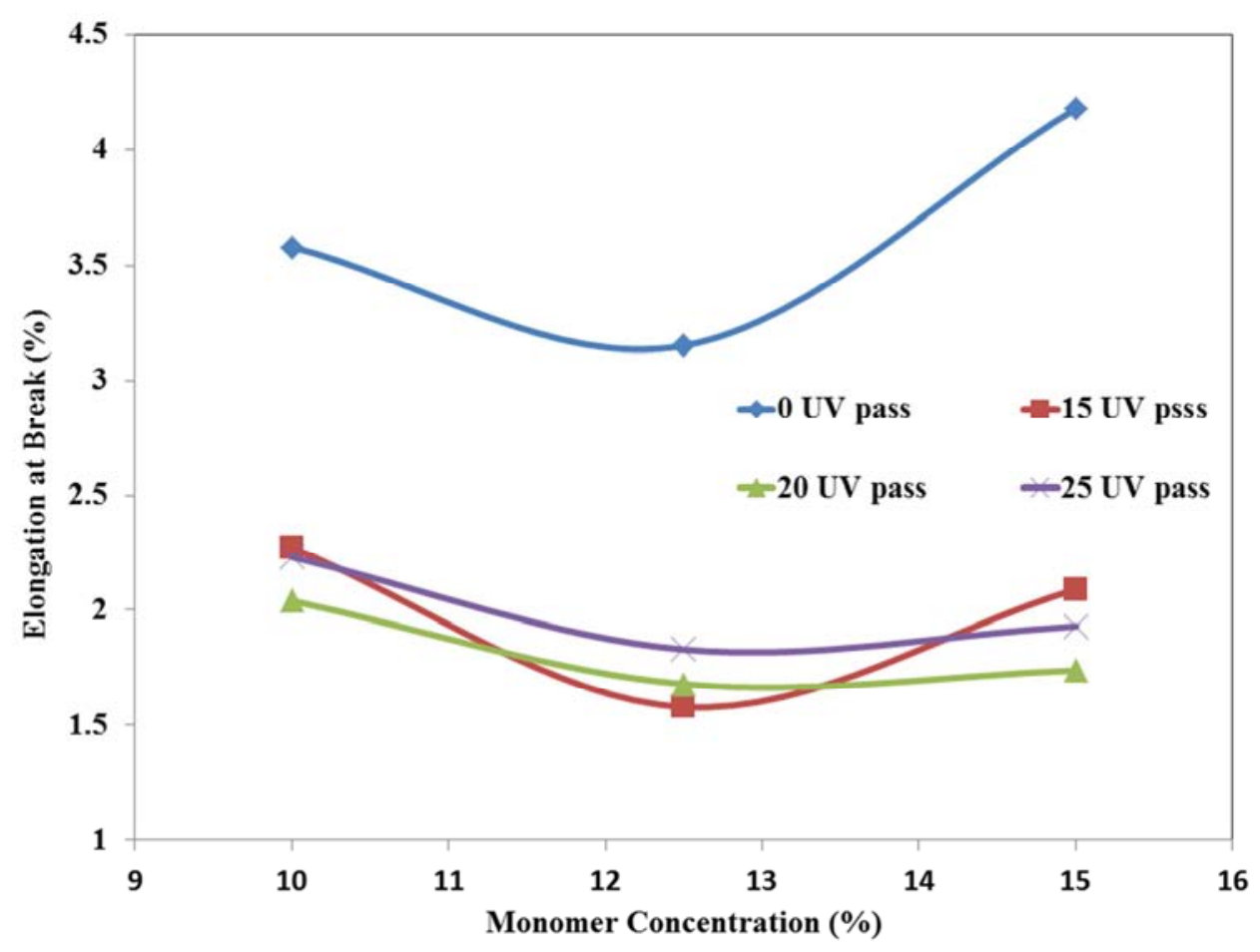

Figure 7. Change of elongation at break at different UV passes and different monomer concentrations.

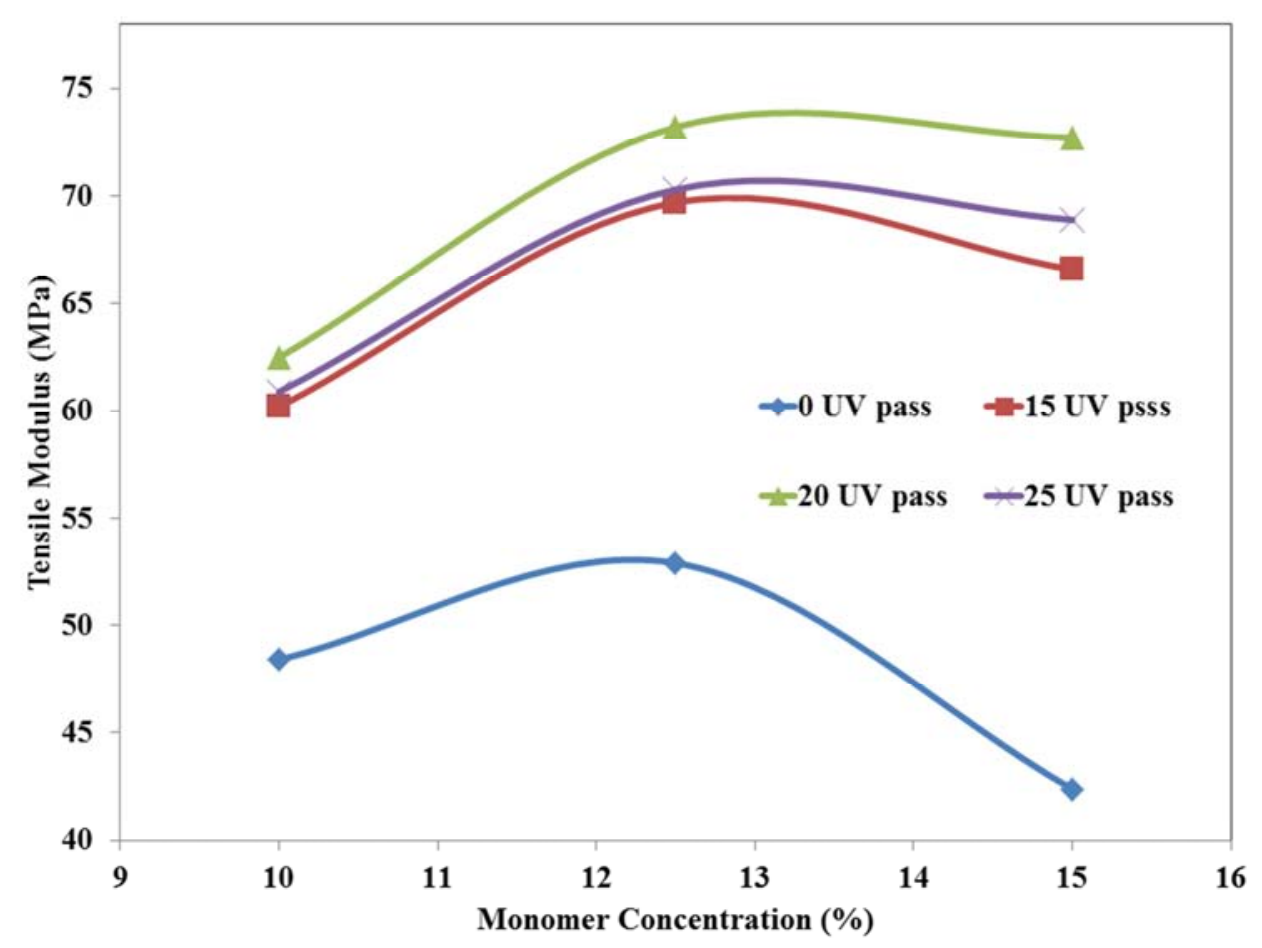

Figure 8. Change of tensile modulus at different UV passes and different monomer concentrations.

\section{Conclusion}

At different percentages of HEMA, the mechanical properties of the films were varied significantly. At the 12.5 HEMA percentage, the best results were obtained. These improved properties may be increased their application fields. If further improvement of film is required then we can apply $20 \mathrm{UV}$ pass through the Catechu films. For the high elongation at break, then non-irradiated 15\% HEMA containing is the best. The highest TS and TM values were measured for the $12.5 \%$ HEMA grafted $20 \mathrm{UV}$ pass films. In short it can be said that $12.5 \%$ HEMA grafted and $20 \mathrm{UV}$ pass irradiation is the best Catechu film. 


\section{Declaration}

The authors declare that there is no conflict of interest regarding this research.

\section{References}

[1] Das, L. R., Mollah, M. Z. I., Islam, J. M. M., Akhter, S., Ahmed, F. and Khan, M. A. (2015) Fabrication of Cellulose Based Reinforced Linear Low Density Polyethylene with Polyethylene Terephthalate Composite: Effect of Acacia catechu as Coupling Agent. Materials Sciences and Applications, 6, 995-1007. http://dx.doi.org/10.4236/msa.2015.611099.

[2] Hye, M. A., Taher, M. A., Ali, M. Y., Ali, M. U. and Shahed, Z. (2009) Isolation of (+)-Catechin from Acacia catechu (Cutch Tree) by a Convenient Method. Journal of Scientific Research, 1, 300-305.

[3] Atta-ur-Rahman, Hakim Mohammed Said, and Viqaruddin Ahmad, Pakistan Encyclopaedia Planta Medica, Hamdard Pakistan 1, 51 (1986).

[4] L. H. Meyer, Food Chemistry (Reinhold Publishing Corporation, New York, 1960) pp 250-251.

[5] M. A. Hye, M. A. Taher, M. Y. Ali, M. U. Ali, and Shahed Zaman, Isolation of (+)-Catechin from Acacia Catechu (Cutch Tree) by a Convenient Method, Journal of Scientific research, 1 (2), 300-305 (2009).

[6] Shibata, M., Takachiyo, K., Ozawa, K., Yosomiya, R. and Takeshi, H. (2002) Biodegradable Polyester Composites Reinforced with Short Abaca Fiber. Journal of Applied $\begin{array}{llll}\text { Polymer } & \text { Science, } & \text { 85, }\end{array}$ http://dx.doi.org/10.1002/app.10665.

[7] Sahadat Hossain, M., Uddin, M. B., Razzak, M., Sarwaruddin Chowdhury, A. M. and Khan, R. A., 2017. Fabrication and characterization of jute fabrics reinforced polypropylenebased composites: effects of ionizing radiation and disaccharide (sucrose). Radiation Effects and Defects in Solids, 172 (11-12), pp. 904-914.

[8] Sahadat Hossain, M., Chowdhury, A. S. and Khan, R. A., 2017. Effect of disaccharide, gamma radiation and temperature on the physico-mechanical properties of jute fabrics reinforced unsaturated polyester resin-based composite. Radiation Effects and Defects in Solids, 172 (5-6), pp. 517-530.
[9] Hossain, M. S., Hossain, M. S., Rahman, M. M., Chowdhury, A. S. and Khan, R. A., 2018. Fabrication and Characterization of Kevlar Fiber Reinforced Polypropylene Based Composite for Civil Applications. Advances in Materials, 7 (4), p. 105.

[10] Rahaman, M. N., Hossain, M. S., Razzak, M., Uddin, M. B., Chowdhury, A. S. and Khan, R. A., 2019. Effect of dye and temperature on the physico-mechanical properties of jute/PP and jute/LLDPE based composites. Heliyon, 5 (6), p.e01753.

[11] Shahriar Kabir, M., Hossain, M. S., Mia, M., Islam, M., Rahman, M., Hoque, M. B. and Chowdhury, A. M., 2018. Mechanical Properties of Gamma-Irradiated Natural Fiber Reinforced Composites. In Nano Hybrids and Composites (Vol. 23, pp. 24-38). Trans Tech Publications.

[12] M. J. Miah, M. A. Khan and R. A. Khan, Fabrication and Characterization of Jute Fiber Reinforced Low Density Polyethylene Based Composites: Effects of Chemical Treatment, J. Sci. Res. 3 (2), 249-259 (2011).

[13] Mohanty, A. K., Khan, M. A. and Hinrichen, G. (2000). Surface Modification of Jute and its Influence on Performance of Biodegradable Jute Fabrics/Biopol Composites, Composites Science and Technology, 60: 1115-1124.

[14] Khan, M. A., Hossain, M. and Ali, K. M. I. (1999). Jute Composite with MMA by Gamma and UV Radiations in the Presence of Additives, Journal of Applied Polymer Science, 74: 900-906.

[15] Mubarak A. Khan, Md. Saifur Rahaman, Abdullah-AlJubayer, and Jahid M. M. Islam, Modification of Jute Fibers by Radiation-Induced Graft Copolymerization and Their Applications, Cellulose Grafted Copolymer, 209-215.

[16] Zaman, H. U., Khan, M. A., Akter, N., Ghoshal, S. and Khan, R. A., 2011. Role of gamma radiation and EGDMA on the physico-mechanical properties of jute fabrics/polypropylene composites. Polymer Composites, 32 (11), pp. 1888-1894.

[17] Zaman, H. U., Khan, A. H., Hossain, M. A., Khan, M. A. and Khan, R. A., 2012. Physico-mechanical, interfacial, degradation, and dielectric properties of jute/PP composites: Effect of dye and Gamma radiation. International Journal of Polymeric Materials, 61 (8), pp. 596-610.

[18] Zaman, H. U., Khan, M. A., Khan, R. A., Rahman, M. A., Das, L. R. and Al-Mamun, M., 2010. Role of potassium permanganate and urea on the improvement of the mechanical properties of jute polypropylene composites. Fibers and Polymers, 11 (3), pp. 455-463. 